\title{
Wide ku-band log periodic dipole array microstrip patch antena using defected ground structure for electronic support measure
}

\author{
Immanuel Wicaksono ${ }^{1 *}$, Dharu $\mathrm{Arseno}^{2}$, Yuyu $\mathrm{Wahyu}^{3}$ \\ ${ }^{1}$ Telecommunication Engineering, Faculty of Electrical Engineering, Telkom University \\ ${ }^{2}$ Indonesian Institute of Science Sangkuriang St., LIPI Office Complex, Building 20, Cisitu, Dago, \\ Coblong, Bandung City, West Java 40135
}

\begin{abstract}
Microstrip antenna as a supporter of wireless communication, which is the development of conventional antenna, has various advantages contained its predecessor, one of which has a patch that can be modified according to the wishes of the user. Microstrip antenna Log Periodic Dipole Array with Defected Ground Structure is one of the patch modification of antenna that allows antenna to work on wideband frequency $12-18 \mathrm{GHz}$ (Ku-Band). Its use is intended for communication on satellites. In this research, will be designed and realized microstrip antenna with modification of Log Periodic Dipole Array patch working on frequency $12-18 \mathrm{GHz}$ (Ku-band). The design will also use modifications to the ground structure with the use of slots using microstrip line feeding techniques. In this research, microstrip antenna design of Log Periodic Dipole Array with Defected Ground Structure works on 12-18 GHz (KuBand) frequency using slot using microstrip line feeding technique, which designed by using application of electromagnetic simulator (Integrated Software). . The desired specifications are; gain $\geq 6 \mathrm{dBi}$, VSWR $<2$, as well as $6 \mathrm{GHz}$ bandwidth, with unidirectional radiation pattern and linear polarization. Substrate materials used in design are Roger 5880 Duroid with a relative permittivity of 2.2 and a dielectric thickness of $1.57 \mathrm{~mm}$. Measurement results on the realization of this tool; return loss on each of the $12,15,18 \mathrm{GHz}$ frequency markers of $-25,457 \mathrm{~dB},-12,939 \mathrm{~dB}$, and $11.004 \mathrm{~dB}$; with the value of VSWR 1.112, 1.593, 1.786. Impedance of $44,988 \Omega, 34,129 \Omega, 27,792 \Omega$. Gain respectively of $8.907 \mathrm{~dB}, 8.931 \mathrm{~dB}$, $8.774 \mathrm{~dB}$. Bandwidth $6 \mathrm{GHz}$. Unidirectional radiation pattern and elliptical polarization.
\end{abstract}

\section{Introduction}

The progress of information and communication technology development, especially in the field of telecommunication today is very fast moving. Renewable creations and innovations are essential in maintaining the quality of the technology provided for the customers themselves. Technology devices, especially in the telecommunications sector,

\footnotetext{
${ }^{1}$ Corresponding author: immancakso@gmail.com
} 
are expected to not only possess qualified technologies but also have the capability, compatibility, and dimensions that support the mobility of the users of the technology itself. The uneasiness that is felt from the high demand of customers is what makes the need of a device provider of a wireless network, the antenna itself.[1]

In this Research, microstrip antenna will be designed which is the development of conventional antenna and has many advantages compared to its predecessor, the dimension of the antenna is small, light and thin, also easy production process because the material is easy to find in the market.[2] However there are some disadvantages such as small bandwidth and small gain. The solution to fix the deficiency is to modify the patch form on the microstrip antenna [3][4].

In the previous research journal, $6 \mathrm{GHz}$ bandwidth was obtained at KU-Band frequency, with a gain of $7.53 \mathrm{~dB}[5]$, which used the patch form Log Periodic Dipole Array. Referring to previous research, this Research is done designing and making microstrip antenna Log Periodic Dipole Array with the addition of Defected Ground Structure which is expected to increase the gain of the antenna itself as well as provide improvements in the values of other parameters desired. The design will use the application of electromagnetic simulator (Integrated Software).

\section{Antenna design}

In this research, the design of microstrip antenna Log Periodic Dipole Array will use copper as groundplane, patch, and feedlinenya. Meanwhile, the substrate will use the Roger 5880 Duroid which has a thin substrate characteristic that is considered suitable for use at high working frequency, wide bandwidth, and supports the use of communications satellites. The characteristics of materials used in this Research are:

1. Copper (copper)

Used because of its nature as a good conductor. The specifications are as follows:

a. Relative permittivity (cr): 1

b. Thickness: $0.035 \mathrm{~mm}$

2. Roger 5880 Duroid

The selection of this material as a substrate is based on the use of antennas at high working frequency, and thin material characteristics, so that it can adjust to the antenna dimensions according to the specified specifications.

1. Relative permittivity (cr): 2.2

2. Thickness: $1.57 \mathrm{~mm}$

The patch form used is the Log Periodic Dipole Array because of its superiority in overcoming the lack of microstrip antenna that has a narrow bandwidth, by adding several elements in-array, so that large bandwidth can be achieved, depending on the amount of working frequency of the desired antenna. This proposed antenna is designed in the following steps which are explained as:

\subsection{Log periodic dipole array MSP antenna without DGS}

Firstly, simple rectangular shaped MSP antenna is calculated and designed with the dimension of $39.651 \times 27.124 \times 1.57 \mathrm{~mm}^{3}$. While the patch is log periodic dipole arrayshaped with the calculation are as table 1 . By simulating this log periodic dipole array MSP antenna, we might achieve the frequency of Ku-Band (12-18 GHz). But still, without the optimization and modification of this antenna structure, we were not getting any frequency in it. Geometry of this structure is shown in Figure1. (a-b). Due to this scenario we achieved its return loss is greater than $-5 \mathrm{~dB}$. So we needed to move to the next modification scenario 
Table 1. Log periodic dipole array MSP antenna without DGS

\begin{tabular}{|c|c|c|c|}
\hline Element & $\mathrm{L}(\mathrm{mm})$ & $\mathrm{d}(\mathrm{mm})$ & $\mathrm{S}(\mathrm{mm})$ \\
\hline 9 & 8.427 & 0.85 & 5.00225 \\
\hline 8 & 7.5253 & 0.759 & 4.467 \\
\hline 7 & 6.7201 & 0.6778 & 3.989 \\
\hline 6 & 6.001 & 0.6053 & 3.5632 \\
\hline 5 & 5.3589 & 0.5405 & 3.181 \\
\hline 4 & 4.7855 & 0.4826 & 2.8406 \\
\hline 3 & 4.2734 & 0.431 & 2.5367 \\
\hline 2 & 3.8162 & 0.3849 & 2.2652 \\
\hline 1 & 3.4878 & 0.3437 & 2.0229 \\
\hline
\end{tabular}

\subsection{Optimized log periodic dipole array MSP antenna without DGS}

The dimension of the rectangular MSP antenna are $124.967 \times 79.782 \times 1.57 \mathrm{~mm}^{3}$ and the calculation of the patch which are as follows:

Table 2. Optimized log periodic dipole array MSP antenna without DGS

\begin{tabular}{|c|c|c|c|}
\hline Element & $\mathrm{L}(\mathrm{mm})$ & $\mathrm{d}(\mathrm{mm})$ & $\mathrm{S}(\mathrm{mm})$ \\
\hline 9 & 17.42749 & 5.5 & 11.5321 \\
\hline 8 & 15.56275 & 4.9115 & 10.29816 \\
\hline 7 & 13.89754 & 4.38596 & 9.19626 \\
\hline 6 & 12.41054 & 3.91667 & 8.21226 \\
\hline 5 & 11.08258 & 3.49758 & 7.33354 \\
\hline 4 & 9.89674 & 3.12334 & 6.54885 \\
\hline 3 & 8.83779 & 2.78914 & 5.84813 \\
\hline 2 & 7.89214 & 2.49075 & 5.22238 \\
\hline 1 & 7.04768 & 2.22423 & 3.18709 \\
\hline
\end{tabular}

In this scenario, we were achieveing the frequency of Ku-Band, but still the return loss is greater than $-10 \mathrm{~dB}$, which is still not a good result yet. So we moved again to the next scenario with the use of defected ground structure. Geometry of this structure is shown in Figure2. (a-b).

\subsection{Modified log periodic dipole array MSP antenna with DGS}

The dimension of the log periodic dipole array MSP antenna was not changed. We only added the defected ground structure with the calculation are as follows:

Table 3. Modified log periodic dipole array MSP antenna with DGS

\begin{tabular}{|c|c|}
\hline DGS parameter & Value $(\mathrm{mm})$ \\
\hline $\mathrm{a}$ & 7 \\
\hline $\mathrm{b}$ & 5 \\
\hline $\mathrm{e}$ & 4.96793 \\
\hline
\end{tabular}

With the addition of DGS, the return loss of this antenna is less than $-10.275 \mathrm{~dB}$, also VSWR is less than 2. Geometry of this structure is shown in Figure3. (a-b). 


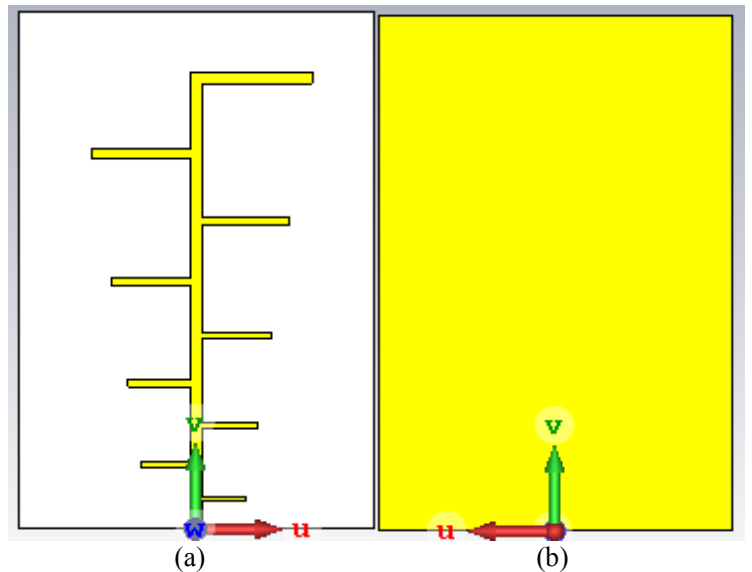

Fig. 1. (a) Log periodic dipole array MSP antenna (b) Back view without DGS

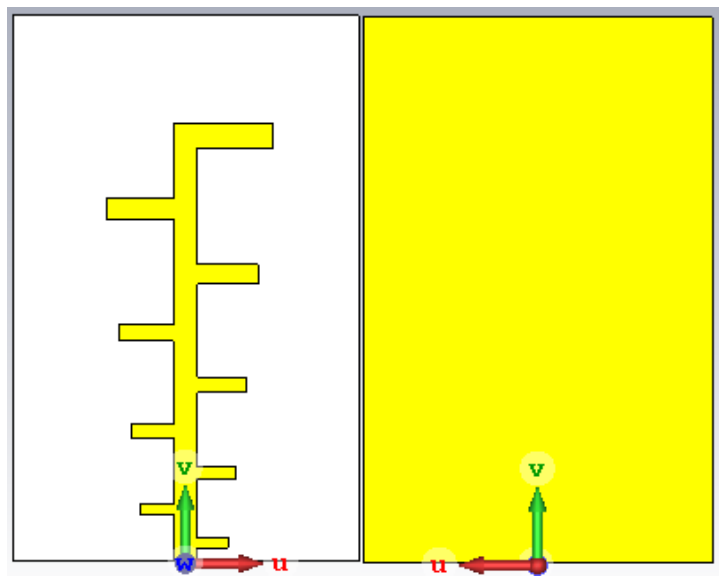

(a)

(b)

Fig. 2. (a) Optimized Log periodic dipole array MSP antenna (b) Back view without DGS

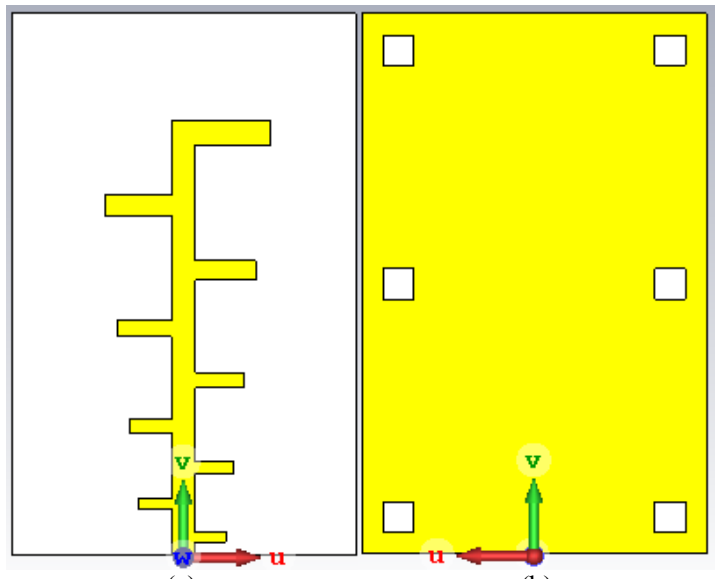

(a)

(b)

Fig. 3. (a) Modified Log periodic dipole array MSP antenna (b) Back view with DGS 


\section{Realization results}

The proposed antenna is simulated using the Electromagnetic (EM) Simulation Software. By using this simulator, we measured return loss, VSWR, Z-Impedance, and farfield radiation pattern (gain, directivity, and efficiency) of the proposed log periodic dipole array shaped MSP antenna.

Moreover, this antenna is realized at PPET LIPI Bandung. These are the results we got from the realization of the LPDA MSP antenna.

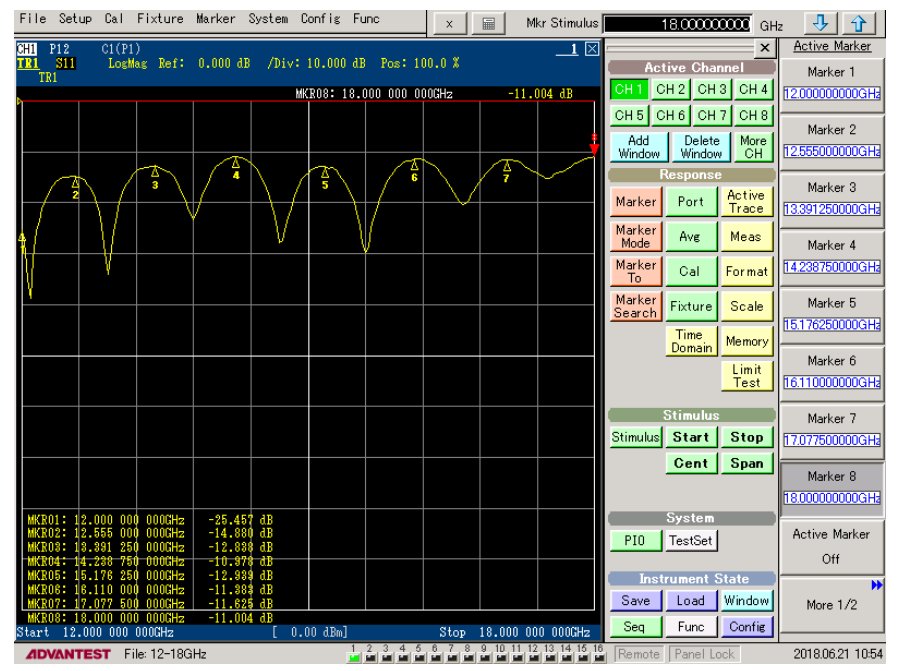

Fig. 4. S11(Return Loss)

The measurement of Return Loss is done by using existing tools in the measurement laboratory at Indonesian Institute of Science (LIPI) using Advantest R3770 Network analyzer $300 \mathrm{kHz}-20 \mathrm{GHz}$. The measurement results are obtained as the explanation below; namely the $12 \mathrm{GHz}$ frequency marker, the value of Return Loss of $-25.457 \mathrm{~dB}$. At the 15 $\mathrm{GHz}$ frequency marker the resulting Return Loss is $-12.939 \mathrm{~dB}$. Then the Return Loss at the $18 \mathrm{GHz}$ frequency marker shows the result $-11.004 \mathrm{~dB}$. The results of this measurement has met the specification with the desired working frequency is also optimal.

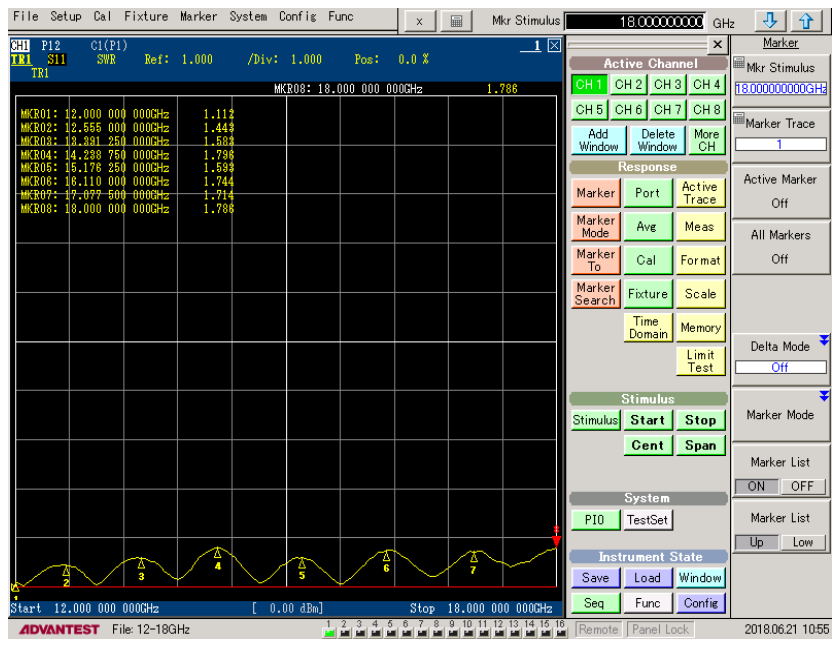

Fig. 5. VSWR 
The measurement of VSWR also use the same hardware. The measurement results are obtained as the explanation below; namely VSWR at $12 \mathrm{GHz}$ with a value of 1.112 . At the $15 \mathrm{GHz}$, VSWR generated at the measurement is 1.593 . While the VSWR at a frequency of $18 \mathrm{GHz}$ shows the results of 1.786 .

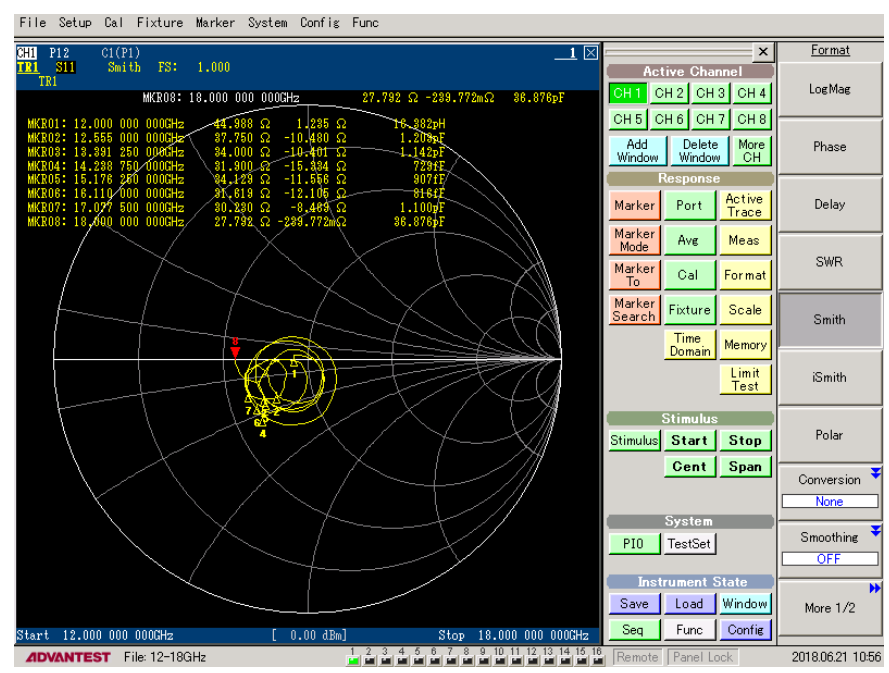

Fig. 6. Z Impedance (Smith Chart)

From Figure6 above, shows that the impedance at $12 \mathrm{GHz}$ frequency marker with value equal to $44.988 \Omega$. At the $15 \mathrm{GHz}$ frequency marker, the impedance is $34.129 \Omega$. While the impedance at the $18 \mathrm{GHz}$ frequency marker shows the result of $27.792 \Omega$. The results are less appropriate with the simulation, which is influenced by the existence of factors affecting the conductor material on the feeding line and the antenna port itself (tin solder material), thus affecting the conduction of feeding.

As the log periodic dipole array using DGS was providing us the $\mathrm{Ku}$-Band frequency, such optimum results of return loss, VSWR, and Z impedance were achieved using this technique.

Pictures below show the comparation of simulation and measurement radiation pattern result:

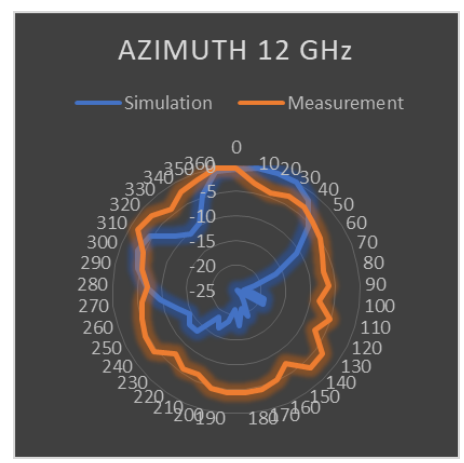

Fig. 7. Azimuth $12 \mathrm{GHz}$ 


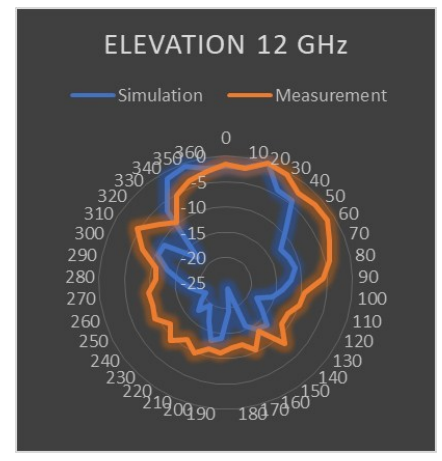

Fig. 8. Elevation $12 \mathrm{GHz}$

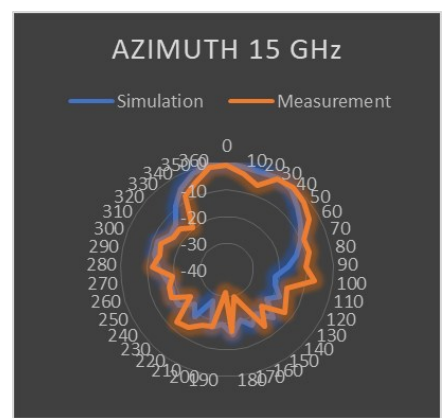

Fig. 9. Azimuth $15 \mathrm{GHz}$

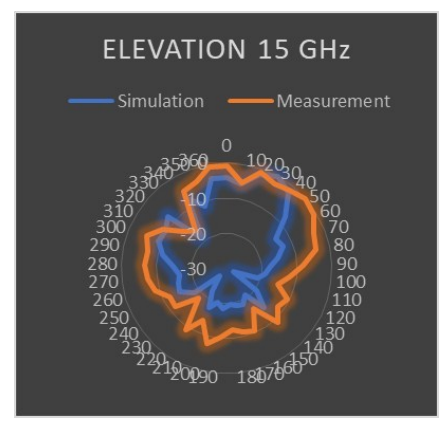

Fig. 10. Elevation $15 \mathrm{GHz}$

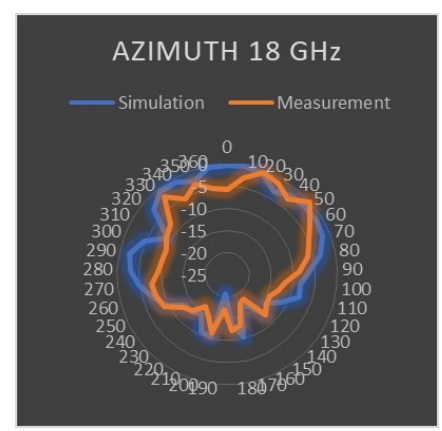

Fig. 11. Azimuth $18 \mathrm{GHz}$ 


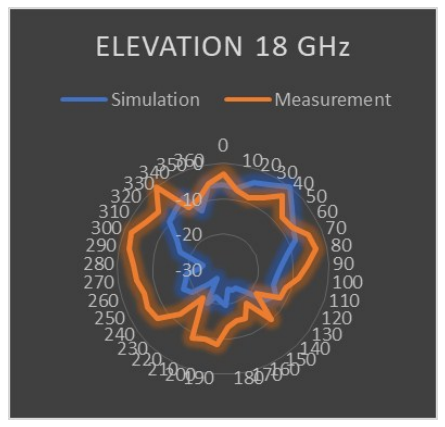

Fig. 12. Elevation $18 \mathrm{GHz}$

In this measurement, the tools used are spectrum analyzer and function generator / sweep. Where the measurement is done in the anechoic chamber at PPET-LIPI Bandung. By definition, the antenna radiation pattern is the output of the ratio of power levels out of the antenna in from various directions. The 6 picture (Figure7 - Figure12) above shows the radiation pattern comparation of simulated and realized antenna.

\section{Conclusions}

A compact wide $\mathrm{Ku}$-Band microstrip patch antenna is proposed. Wide Ku-Band (12-18 $\mathrm{GHz}$ ) is achieved using defected ground structure. Proposed antenna dimensions are 39.651 X 27.124 X $1.57 \mathrm{~mm}^{3}$. We use Roger 5880 Duroid substrate with dielectric constant 2.2 and thickness $1.57 \mathrm{~mm}$ is used. For improving the return loss and VSWR of the antenna, Log Periodic Dipole Array MSP antenna with Defected Ground Structure is introduced. All antenna parameters that have been planned in the early stages of the antenna design already meet the desired specifications, ie for Return Loss $\leqslant-10.27 \mathrm{~dB}$, VSWR $\leqslant 1.883,6 \mathrm{GHz}$ Bandwidth on Ku-Band frequency, Unidirectional Radiation Pattern, Linear Polarization, $50 \Omega$ Input Impedance, and Gain $\geqslant 8.774 \mathrm{~dB}$. The main application of proposed antenna is to make compatible with Ku-Band frequency used-devices which covers maximum satellite applications (Electronic support measure, mobile satellite, fixed satellite, aeronautical radio navigation, radiolocation, space research, etc.)

\section{References}

1. SATMARIN. L-BAND, C-BAND, KU-BAND AND KA-BAND. (2018, March 22).

2. Ramesh Garg, P. B. Microstrip Antenna Design Handbook. Artech House Inc. (2001)

3. Denny, M. KU-Band Log Periodic Microstrip Antenna for Electronic Support Measure. (2017)

4. Firmansyah, T. Herudin., et al. "Bandwidth and gain enhancement of MIMO antenna by using ring and circular parasitic with air-gap microstrip structure". Telkomnika (Telecommunication Computing Electronics and Control). Vol.15(3). Pp. 1155-1163. 2017.

5. Firmansyah, T., Herudin, et a."Multiband microstrip antenna array with slot and array method for GSM, WCDMA, and LTE". International Conference on Broadband Communication, Wireless Sensors and Powering (BCWSP). Pages 1-5. 2017.

6. Fermando, D. Phased Array Microstrip Antenna for $1.27 \mathrm{GHz}$ Synthetic Aperture Radar. (2017)

7. Balanis, C. A. Antena Theory Analisis and Design 3rd Edition. United Science: Wiliey Inter Science. (2005) 
8. Krauss, J. D. Antennas. United Stated: Wiliey Inter Science. (1998)

9. Sujati, I. Antena Mikrostrip : Konsep dan Aplikasinya. Jakarta: Universitas Trisakti. (2010)

10. Ardiansyah, R. Ultra Wide Band Log Periodic Misrostrip Patch Antenna for Electronic Support Measure 2-18 GHz. (2017)

11. Bhadouria, A. S., \& Kumar, M. Wide Ku-Band Microstrip Patch Antenna Using Defected Patch and Ground. IEEE International Conference on Advances in Engineering \& Technology Research (ICAETR - 2014). Unnao, India: Dr. Virendra Swarup Group of Institutions. (2014)

12. Weng, L. H., Guo, Y. C., Shi, X. W., \& Chen, X. Q. (2008). An Overview on Defected Ground Structure. In Progress In Electromagnetics Research B Vol. 7 (pp. 173-189).

13. Lampiran Permen Tasfri (Departemen Komunikasi dan Informatika Republik Indonesia, 2009)

14. Microstrip Patch Antenna Calculator. Retrieved from everythingRF. (2015) 